\title{
CONFIGURACIÓN DE LA OBLIGACIÓN DE ENTREGAR A TRAVÉS DE LA AUTONOMÍA PRIVADA: DERECHOS DE TERCEROS
}

["Constitution of the Obligation of Delivery by Way of the Private Autonomy: Third-party Rights"]

\author{
IÑIgO DE LA MAZA GAZMURI* \\ Universidad Diego Portales, Santiago de Chile
}

\begin{abstract}
Resumen
¿Exige la obligación de entrega del vendedor un traspaso libre de derechos de terceros? La respuesta es que depende, y depende del acuerdo de las partes. $\mathrm{Si}$ nada han convenido, el vendedor cumple haciendo el traspaso material de la cosa y frente a la existencia de derechos de terceros, el comprador únicamente puede invocar la protección del régimen de la evicción. Si han convenido una entrega libre de derechos de terceros, entonces el traspaso de una cosa con este tipo de
\end{abstract}

\begin{abstract}
Does the seller's obligation to deliver demands the free delivery of third-party's rights? The answer is that it depends, and it depends on the agreement reached by the parties. If there is no agreement, the seller fulfills his/her obligation by materially delivering the thing and if there are third-party rights, the buyer can merely invoke the regime's protection from eviction. If they have agreed on a free delivery of third-party's rights, then the delivery of a thing with this kind of rights constitutes
\end{abstract}

RECIBIDO el 27 de agosto y APROBADo el 1 de octubre de 2012

* Doctor en Derecho por la Universidad Autónoma de Madrid; profesor de Derecho Civil e investigador en la Facultad de Derecho de la Universidad Diego Portales. Dirección postal: República 105, Santiago de Chile. Correo electrónico: inigo.delamaza@udp.cl. Este artículo se enmarca en el Proyecto FONDECYT regular No 1120548 , titulado: "El tratamiento de las entregas defectuosas en el derecho chileno: hacia una noción de incumplimiento amplia y unitaria". 
derechos constituye incumplimiento de la obligación de entrega que autoriza al comprador a recurrir a los remedios generales del incumplimiento contractual.

\section{Palabras Clave}

Compraventa - Entrega - Evicción - Autonomía Privada - Remedios del incumplimiento contractual. a breach of the obligation of delivery that authorizes the buyer to resort to the general remedies for breach of contract.

\section{KEYWORDS}

Purchase and sale - Delivery - Right of Possession - Private Autonomy - Remedies for breach of contract.

\section{INTRODUCCIÓN}

En este trabajo me interesa reflexionar acotadamente sobre la forma en que nuestros tribunales han entendido la obligación de entrega. Digo "acotadamente" porque examinaré esta compleja cuestión tan solo desde uno de sus ángulos: la existencia de derechos de terceros sobre la cosa que resultan incompatibles con la posición que el comprador estima garantizada por el contrato de compraventa. En otras palabras, me interesa considerar si el vendedor que traspasa material y jurídicamente una cosa sobre la cual existen derechos de terceros cumple o no con su obligación de entrega.

Estimaré que una entrega en la que existen derechos de terceros es una entrega imperfecta. El punto consiste en determinar si esa entrega imperfecta constituye, en los términos del artículo $1824 \mathrm{CCCh}$. un incumplimiento de la obligación de entrega o bien, únicamente, activa la protección del régimen de la evicción.

Mi respuesta es que depende. Y depende de la autonomía privada. Para desarrollar esta posición asumiré que, naturalmente, el vendedor no está obligado a transferir el dominio de la cosa, por lo tanto, a fortiori, tampoco está obligado a entregar una cosa libre de derechos de terceros. Sin embargo, esta consecuencia natural -en el sentido del artículo 1.444 CCCh.- puede alterarse cuando las partes han convenido que se debe una entrega libre de derechos de terceros.

\section{LA OBLIGACIÓN DE ENTREGA: QUÉ Y CÓMO}

La correcta comprensión de la obligación de entrega en el contrato de compraventa exige responder, al menos, dos preguntas. La primera de ellas es qué debe entregarse, la segunda consiste en determinar cómo debe entregarse.

Ambas preguntas han ocupado a los tribunales y a la doctrina. Así, por 
ejemplo, en el considerando séptimo de una sentencia de la Corte Suprema de 8 de septiembre de $2009^{1}$ se lee: "Que, como se ha dicho, conforme lo expresa el artículo 1824 del Código Civil el contrato de compraventa genera respecto del vendedor dos obligaciones principales: 'la entrega o tradición, y el saneamiento de la cosa vendida'./ La doctrina y la jurisprudencia han expresado que la norma en referencia hace uso del lenguaje con mayor propiedad, puesto que alude a la obligación general de 'entrega', que comprende: 1) la de conservar la cosa hasta su entrega; 2) la de responder por los deterioros producidos por el hecho o culpa del vendedor; 3) la de poner la cosa a disposición del comprador, es decir la obligación de entregar propiamente dicha; 4) la de entregarla en el tiempo $y$ lugar convenidos; 5) la de costear los gastos que se hicieren para ponerla en disposición de ser entregada; y 6) la de entregarla con todos sus frutos y accesorios (Arturo Alessandri Rodríguez, De la Compraventa y de la Promesa de Venta, Editorial Jurídica de Chile, año 2003, Tomo I, Volumen 2, páginas 573 y 574$)^{\prime \prime 2}$.

$\mathrm{Al}$ considerar la forma en que se desagrega la obligación de entrega es posible advertir que los números 1) y 2) corresponden a obligaciones previas al acto mismo de la entrega. Los números 3), 4) y 5), en cambio, se refiere a cómo debe realizarse la entrega. Finalmente, el número 6) se refiere a qué debe entregar. Los dos números más relevantes, en mi opinión, son el 3) y el 6).

El número 3) responde a la principal pregunta acerca de cómo ha de entregarse. Sobre esto, convendrá seguir precisando acerca de qué ha de entenderse por "poner la cosa a disposición del comprador". Una vez más, los Tribunales y la doctrina parecen estar de acuerdo. Así se desprende, por ejemplo, de la sentencia de la Corte Suprema de 10 de octubre de $2007^{3}$, en cuyo considerando quinto se lee: "Si bien, según lo señala el artículo 686 del Código Civil, la tradición del dominio de los bienes raices se lleva a cabo por la inscripción del titulo en el Registro del Conservador, no lo es menos que, para que la obligación se cumpla integramente es menester -como lo señala la doctrina, por todos, el catedrático de Derecho Civil, Prof. Ramón Meza Barros, en este orden de consideraciones y similitud de enfoque (Manual de Derecho Civil. De las fuentes de las obligaciones. Editorial Jurídica de Chile, Santiago de Chile, 1.966, tomo I, págs, 122 y sgtes., correspondientes) - que el vendedor proporcione al comprador no tan solo la posesión legal, sino que también la po-

${ }^{1}$ Corte Suprema, sentencia de 8 de septiembre de 2009, cita Westlaw: CL/ JUR/877/2009.

${ }^{2}$ La misma cita de Alessandri Rodríguez se encuentran en la sentencia de la Corte Suprema de 5 de agosto de 2009, cita Westlaw: CL/JUR/9459/2009.

${ }^{3}$ Corte Suprema, sentencia de 10 de octubre 2007, cita Westlaw: CL/ JUR/2177/2007. 
sesión material de la cosa, y a que la posesión legal del inmueble, sin su tenencia material, no brinda al comprador las ventajas que persigue el contrato".

En un sentido similar una sentencia de la Corte de Apelaciones de Concepción de 18 de mayo $2000^{4}$, en su considerando quinto: "La obligación de entrega, a su turno, se traduce en aquella del vendedor que tiene por objeto dar la posesión legal y material de la cosa al comprador".

Por poner la cosa a disposición del vendedor ha de entenderse, entonces, proporcionarle a éste su posesión legal y material.

Respectó a la pregunta acerca de qué debe entregarse, el número 6) es bastante parco: la cosa con todos sus frutos y accesorios. El problema, en mi opinión, consiste en determinar qué vamos a entender por "la cosa". Esta pregunta puede llegar a ser extremadamente amplia y abarcar cuestiones relacionadas con la doctrina del aliud pro alio, de los vicios redhibitorios, de la cabida y de la evicción entre otros ${ }^{5}$. En este trabajo me interesa centrarme en una sola de esas cuestiones: la existencia de derechos de terceros y la pregunta ha de ser ¿cumple con su obligación de entrega quien transfiere material y jurídicamente una cosa con derechos de terceros incompatibles con la posición jurídica que el contrato busca asegurar?

\section{ENTREGA, DERECHOS DE TERCEROS Y EVICCIÓN}

Para comenzar a pensar la respuesta a esta pregunta resultará útil detenerse con algún detalle sobre una sentencia de la Corte de Apelaciones de Valdivia de 16 de noviembre de $2009^{6}$.

Los hechos son los siguientes, con fecha 12 de abril de 2001 se otorgó por escritura pública la venta de un predio de 493,96 hectáreas ubicado en la comuna de Los Lagos propiedad del Banco Santander a don Rodrigo Toro Mancilla. El predio se vendió: "ad corpus en el estado en que se encuentra lo vendido y que la parte compradora declara conocer y aceptar, con sus derechos, usos, costumbres y servidumbres activas y pasivas, libre de todo gravamen, probibición, embargo y juicio pendiente".

Según consta en el contrato, el predio se le entregó materialmente al comprador a su entera satisfacción. Sin embargo, a comienzos de 2001, ciertos terceros que alegaban derechos sobre el predio adquirido incurrieron,

${ }^{4}$ Corte de Apelaciones de Concepción, sentencia de 9 de enero de 2002, cita Westlaw: CL/JUR/1335/2002.

${ }^{5}$ Me he referido someramente a todo esto en DE LA MAZA Gazmuri, Iñigo, $E l$ régimen de los incumplimientos defectuosos en la compraventa (inédito).

${ }^{6}$ Corte de Apelaciones de Valdivia, sentencia de 16 de noviembre de 2009, Identificador Microjuris MJJ22361. 
en ocasiones, en vías de hecho, ocupando diversos sectores del predio y, en otras ocasiones, en acciones judiciales.

En consideración a estas circunstancias el comprador decidió demandar indemnización de perjuicios al Banco por incumplimiento de sus obligaciones contractuales. Acertadamente, el tribunal de primera instancia consideró que el asunto que debía resolver: "Radica en determinar si efectivamente ha existido un incumplimiento contractual por parte del demandado y ello ba causado los perjuicios alegados y si proceden ser indemnizados; en caso que lo fueren, habrá que determinar la naturaleza y el monto de aquellos".

La respuesta que entregó la jueza de primera instancia a esta pregunta fue que el incumplimiento contractual se había producido por el solo hecho de que existiesen perturbaciones de hecho y otras en sede judicial. La jueza entendió que como se había pactado que el predio se entregaba libre de todo gravamen "sobre el demandado pesaba la obligación de entregar el predio [...] libre de todo ocupante”. La razón es que la obligación de dar no se agota en la transferencia material y jurídica, sino en una entrega que permita el ejercicio de las facultades de uso y goce. Concluye de la siguiente manera: "al transferir el dominio del predio en cuestión sabiendo que habia problemas de deslindes, que la superficie no correspondia a la realidad, que existian otros ocupantes reclamando derechos sobre éste, el demandado causó un daño al actor porque si bien no vendió cosa ajena, el contrato fue imperfecto, dado que no cumplió con su obligación de entrega como correspondia, porque no confirió la tenencia material de la cosa, ello en conformidad a lo dispuesto en los artículos 1548 y 1793 del Código Civil".

Estos razonamientos no persuadieron a la Corte de Apelaciones de Valdivia. El tribunal de alzada consideró que no existía incumplimiento de la obligación de entrega, en los siguientes términos: “[...] desde una perspectiva estrictamente jurídica, es parecer de esta Corte que la hipótesis sub lite no puede configurar per se un incumplimiento contractual que pueda dar origen directamente a una indemnización de perjuicios. Las razones para arribar a esa conclusión son las siguientes: A) La doctrina y la jurisprudencia de los Tribunales tienen largamente establecido que no incumple con su obligación de entregar el vendedor que entrega física y juridicamente la cosa, pero no hace dueño al comprador, en razón de que no era dueño del bien de que se trataba. Tal aseveración se funda lógicamente en la plena validez de la venta de cosa ajena, declarada formal y explícitamente por el artículo 1815 del Código Civil, y en la existencia de la obligación de garantia, que comprende la obligación de saneamiento de la evicción, dentro de las obligaciones naturales del contrato de compraventa".

La Corte, entonces, considera que la obligación de entrega se cumple con la entrega física y jurídica de la cosa, aun cuando tenga derechos de 
terceros. Así lo desprende del artículo 1.815 y de la existencia de la obligación de saneamiento de la evicción. Conviene considerar brevemente estos argumentos por separado.

Respecto del artículo 1.815, el Tribunal considera: "Que, entonces, si jurídicamente no constituye incumplimiento contractual (de la obligación de entregar en la compraventa) el hecho de que todo el objeto del contrato (la totalidad del predio, en la especie) resulte ser de dominio ajeno, entonces, a fortiori, menos puede serlo la circunstancia de que una sección menor del mismo sea objeto de disputa dominical, como ocurre en la especie".

La idea de que el vendedor no se obliga a transferir el dominio parece suficientemente asentada en nuestro Derecho. Como ha sugerido José Joaquín Ugarte, ésta ha sido la posición "abrumadoramente mayoritaria" en Chile 7 . Un buen ejemplo de lo anterior se encuentra en Alessandri Rodríguez, según cuya posición reza así: "[Nuestro Código] (R)eprodujo [...] la regla romana, según la cual el vendedor se obliga a poner al comprador en posesión tranquila y pacífica de la cosa vendida de modo que, entre nosotros, aquel no se obliga a dar la propiedad al comprador".

Ahora bien, del hecho que pueda cumplirse con la obligación de entrega aun cuando la cosa tenga derechos de terceros no se sigue que el comprador quede desprotegido frente a esta situación. El segundo argumento de la Corte de Apelaciones se refiere a esta consideración, es decir, se refiere al saneamiento de la evicción. En los siguientes términos. "En consecuencia, el vendedor no incumple cuando no hace dueño al comprador, porque su obligación no era hacerlo dueño; su obligación es proporcionarle una posesión pacifica y útil, y para ello se consagran el especifico mecanismos de la citación de evicción $y$ las determinadas acciones redhibitoria y quanti minoris, que concretan la responsabilidad del vendedor, estableciendo las obligaciones de defensa judicial para el caso de amenaza judicial de pérdida total o parcial de la cosa y de indemnización subsidiaria para el caso de concretarse ese riesgo; la posibilidad de rescindir y la obligación de indemnizar cuando los vicios ocultos son tales que afectan gravemente la funcionalidad del bien; y la obligación de rebajar el precio en caso contrario [...]. Que la situación sub lite, en que el comprador ha sufrido turbaciones y quizá (aunque no se haya probado) una evicción parcial del predio adquirido, está expresamente prevista como materia de citación de evicción, en los artículos 1852, 1853 y 1854 del Código Civil [...]. En otros términos, resulta palmario que el legislador sujeta la indemnización de los

${ }^{7}$ Ugarte Godoy, Joaquín, La obligación esencial del vendedor de transferir el dominio, en MAC Hale, Thomas - Del VAlle, Jaime, Estudios en honor a don Pedro Lira Urquieta (Santiago, Editorial Jurídica de Chile, 1970), p. 151.

${ }^{8}$ Alessandri Rodríguez, A., De la compraventa y de la promesa de venta (reimpresión Santiago, Editorial Jurídica de Chile, 2003), I,2, p. 659. 
perjuicios, también en caso de evicción parcial, al hecho de no haberse cumplido con la natural obligación de saneamiento que incumbe a todo vendedor, obligación para cuya procedencia concreta es menester, de modo indispensable, que se lo cite legalmente. Desde luego, si se pensara que existe conflicto normativo entre el contenido de estas normas y las generales sobre indemnización de daños contractuales ( $y$ a juicio de esta Corte, no lo hay, se trata simplemente de una especificación legislativa respecto de la necesidad de constituir en mora respecto de la obligación de defensa) tendrán aplicación preferente las primeras, simplemente en aplicación del principio de especialidad: Lex specialis derogat legi generali".

Lo que señala el Tribunal es que la existencia de derechos de terceros no es una cuestión que corresponda a la obligación de entrega, sino a la de saneamiento de la evicción. De manera que, en este caso, si el comprador deseaba solicitar indemnización de perjuicios debía hacerlo al amparo de las reglas de la evicción, no de las generales del incumplimiento.

La razón es que respecto de este tipo de cumplimiento defectuoso existe una regla especial (la de la evicción) que desplaza a la general por incumplimiento de la obligación de entrega'. Para decirlo de otra manera, el Tribunal parece estimar que, en algún sentido, la entrega ha sido defectuosa, sin embargo, existe una regla especial para ese tipo de entregas (con derechos de terceros) que resulta especial respecto de las reglas generales sobre incumplimiento de la obligación de entrega ex artículo 1826 CCCh..

Añade la Corte de Apelaciones que entender las cosas de otra manera simplemente distorsiona el sistema del incumplimiento contractual y los remedios. En los siguientes términos: "Que no entenderlo así, como hace la sentencia de primer grado, produce una importante distorsión del completo sistema de obligaciones contractuales y remedios legales frente a incumplimientos derivados del contrato de compraventa de inmuebles, al margen de afectar de modo decisivo el principio de conservación del negocio jurídico. En efecto, comprender la regulación legal de ese sistema de obligaciones y remedios del modo como lo ha hecho la sentencia en alzada supone alterar la voluntad legislativa,

${ }^{9}$ El principio de especialidad -que plasma el adagio specialia generalibus derogantconstituye un dispositivo frecuente en la solución de antinomias normativas. Sobre esto puede consultarse, en la literatura nacional, SQuella Narducci, A., Introducción al derecho (Santiago, Editorial Jurídica de Chile, 2011), pp. 465-476. Así, por ejemplo, en el derecho francés y español se ha empleado para resolver cuestiones de concurrencia entre acciones de nulidad por error y acciones redhibitorias. Para el derecho francés puede consultarse GOLDIE-GENICON, Ch., Contribution à l'étude des rapports entre le droit commun et le droit special des contrats (París, LGDJ, 2009), pp. 262-268; respecto del derecho español puede consultarse: Verda y Beamonte, Jr., Saneamiento por vicios ocultos, (2a edición, Cizúr Menor, Aranzadi Thonson Reuters), pp. 49-54. 
a la cual deben imperativo acatamiento los jueces, en al menos los siguientes puntos. Primero, altera la regla invariable de que el alcance de la obligación de entregar se refiere a la posesión y no al dominio, permitiendo que se deje sin efecto el contrato y se pida indemnización de perjuicios (y aún, como hace la sentencia en alzada, sólo lo segundo, independizando la indemnización de la resolución o el cumplimiento forzado) cuando existan cuestionamientos dominicales, aún parciales, sobre la cosa. Segundo, hace meramente optativa para el comprador la obligación legal imperativa del artículo 1843 del Código Civil, que estipula que 'el comprador a quien se demanda la cosa vendida, por causa anterior a la venta, deberá citar al vendedor para que comparezca a defenderla' $y$ desoye el mandato legal del inciso tercero de ese mismo articulo que dispone que 'si el comprador omitiere citarle, y fuere evicta la cosa, el vendedor no será obligado al saneamiento; $y$ si el vendedor citado no compareciere a defender la cosa vendida, será responsable de la evicción; a menos que el comprador haya dejado de oponer alguna defensa o excepción suya, y por ello fuere evicta la cosa"': Esa disposición legal, como se ve, exime de responsabilidad al vendedor que no es citado de evicción.

En el derecho nacional, junto a la sentencia de la Corte de Apelaciones de Valdivia existe, al menos, otra en que la Corte de Apelaciones de Concepción parece haber razonado de la misma manera. Se trata de una sentencia de 9 de enero de 2002 que confirma la del tribunal de instancia de fecha 9 de mayo de $2000^{10}$. Los hechos corresponden a la venta de un taxibús que, a la fecha del contrato, se encontraba prendado a favor de un tercero. Cinco meses después de la venta el vehículo fue retirado de circulación por una orden judicial pues el demandado (el vendedor) no había cumplido con sus obligaciones contraídas al adquirir el vehículo. El comprador demandó la resolución del contrato, alegando incumplimiento de la obligación de entrega pues, en su opinión, la entrega debía realizarse sin limitaciones al dominio. El tribunal de instancia y la Corte de Apelaciones de Concepción consideraron que no había existido incumplimiento de la obligación de entrega pues ésta limitaba su alcance al traspaso legal y material de la cosa. "El vendedor -señala el tribunal- no se obliga a dar la propiedad al comprador, sino a constituirlo en poseedor". Y añade: "Otra cosa y muy distinta a la infracción de la obligación de entrega lo constituye el hecho que el actor se haya visto turbado en la posesión pacifica y tranquila del vehiculo por vias de derecho el embargo y retiro de que habla en su demanda toda vez que esto cae en el campo de la obligación de saneamiento y especificamente de la evicción".

${ }^{10}$ Corte de Apelaciones de Concepción, sentencia de 9 de enero de 2002, cita Westlaw CL/JUR/1334/2002 y Tribunal de letras, 9 de mayo de 2000, cita Westlaw CL/JUR/703/2000. 
En la misma demanda (fs. 22) se reconoce que el taxibús estuvo seis meses en poder del demandante y, en razón de ello, malamente puede discurrirse acerca de la vulneración de la obligación de entrega, pues todos los tópicos de argumentación enderezados para tales efectos en el escrito de demanda redundan en el fondo en una supuesta infracción a la obligación de saneamiento que evidentemente, es ajena a la fundamentación de la acción resolutoria intentada.

Como puede verse, esta sentencia de la Corte de Apelaciones de Concepción se encuentra alineada con la de la Corte de Apelaciones de Valdivia. En definitiva los cumplimientos defectuosos que se explican por la presencia de derechos de terceros no configuran incumplimiento de la obligación de entrega pues existe una norma especial que se ocupa de ellos.

Pues bien, al abrigo de estas sentencias y de la opinión de la doctrina, parece ser que el vendedor no está obligado a entregar la cosa libre de derechos de terceros y, por lo tanto, si lo hace no incumple con la obligación de entrega. Esto no significa que el comprador quede desprotegido frente a esta circunstancia, sino más bien que su protección es aquella que le franquea la disciplina de la evicción.

\section{LA OBLIGACIÓN DE ENTREGA REVISITADA}

Conviene, sin embargo, no apresurar demasiado las conclusiones. Una sentencia de la Corte de Apelaciones de Concepción de 1 de diciembre de $1993^{11}$ nos enseña por qué.

Los hechos son relativamente sencillos. Por escritura pública de 26 de febrero de 1988 doña María Luisa Dosque Contreras vendió a Transportes Sierra Nevada Limitada el departamento número once del primer piso del Bloque A, en la Población Remodelación Lautaro de Penco. En la cláusula cuarta de dicha compraventa las partes establecieron que la venta se hacía en el estado que se encuentra actualmente el departamento, con todos sus usos, derechos, costumbres y servidumbres, libre de todo gravamen, prohibición y embargo, con todo lo edificado y planteado.

No obstante lo anterior, y con posterioridad a la entrega material del inmueble, la compradora constató que el predio se encontraba gravado por una hipoteca a favor del Banco del Estado de Chile por la suma de 620 unidades de fomento y que también existía una prohibición de gravar, enajenar y arrendar, a favor del mismo Banco.

Frente a esta situación la compradora dedujo una acción de cumplimiento

${ }^{11}$ Corte de Apelaciones de Concepción, sentencia de 1 de diciembre de 1993, cita Westlaw Chile: CL/JUR/66/1993. 
forzado de la obligación de entrega, pidiendo, concretamente que se obligara a la vendedora a alzar el gravamen y prohibición y que no haciéndolo se le embargaran bienes suficientes para lograr ese alzamiento.

La demandada no contestó la demanda, sin embargo, en la duplica señaló que había cumplido sus obligaciones pues había hecho la tradición y la entrega material del inmueble. Por otra parte, señaló, la obligación de saneamiento no se encontraba incumplida pues hasta el momento la compradora no había sido privada de la cosa.

Interesan a estas páginas las consideraciones de la Corte de Apelaciones de Concepción respecto del incumplimiento contractual alegado ${ }^{12}$. $Y$ hay pocas maneras más correctas de formular la cuestión que aquella empleada por el tribunal de alzada en el Considerando sexto de su sentencia: "Que de ese modo, la cuestión a decidir, en primer término, es si la obligación de entregar la cosa vendida, que el artículo 1824 del Código Civil pone de cargo del vendedor, comprende o no la de transferírsela libre de gravámenes o derechos en favor de terceros, cuando el vendedor ha declarado vender una especie libre de ellos y si, por lo mismo, la demandada ha cumplido o no esa obligación".

Sobre esta cuestión, la sentencia comienza advirtiendo que el Código Civil impone al vendedor la obligación de entrega de la cosa vendida y la de garantía de que ella no contiene vicios ocultos, así como la de responder de su evicción. Señala, a continuación, que la obligación de entrega involucra tanto el traspaso material de la cosa como su tradición. En tercer lugar, fija aquello que debe entregarse en los siguientes términos: "Pero lo que el vendedor ha de entregar es la misma cosa que se individualiza en el contrato y esa obligación sólo se cumple si lo entregado es la cosa tal y como ha sido convenida, de forma que, faltándole alguna parte o afectándole algún derecho en favor de un tercero que pueda producir su evicción, el vendedor no ha cumplido cabalmente su obligación".

En cuarto lugar, lo sentenciadores se hacen cargo de la ligazón existente entre la obligación de entrega y el saneamiento de la evicción. Y aquí conviene citar con generosidad. "Que, si bien el Código Civil distingue la obligación de entregar de la de saneamiento de la evicción, ello no ha de llevar a la conclusión que se trate de obligaciones absolutamente desligadas, de forma que, habiéndose hecho la tradición y la entrega material, esté cumplida la primera y que todo derecho existente en favor de terceros sobre la cosa sea objeto únicamente de la obligación de saneamiento de la evicción./ En efecto, como lo sostienen autorizados doctrinadores, si la cosa vendida está gravada con cargas o si existen derechos de terceros o aun si la cosa es ajena, la obligación de saneamiento se

${ }^{12}$ Por lo mismo no me detendré en las razones que justificaron su negativa a acoger las pretensiones de la demandante, 
hace efectiva desde que el tercero reclame su derecho, en tanto que, mientras ello no suceda, si el comprador advierte la existencia de tales derechos, aunque no reclamados por su titular, puede prevalecerse de las acciones a que da lugar el cumplimiento de la obligación de entregar (así, F. Messineo, Manual de Derecho Civil y Comercial, t. 5 n. 18, pág. 98)./ Esa conclusión, que otras legislaciones han pormenorizado en reglas explícitas (por ejemplo, artículo 1489 Código Civil italiano), es también la que resulta de las normas de nuestro Código, si se tiene presente lo prevenido en los artículos 1828, 1838, 1843 y 1489 del Código Civil./ En efecto, el vendedor está obligado a entregar lo que reza el contrato, regla dispuesta a propósito de la obligación de entregar (párr. 6 Tít. XXIII, Lib. IV) y que hace de la obligación de entregar no solamente un paso material y jurídico de la cosa, sino también comprender en ella, una identidad entre aquello que forma el objeto de la obligación y lo efectivamente entregado, puesto que, en definitiva, no se trata sino de la particularización de la regla general del artículo 1569 que impone como requisito objetivo del cumplimiento la exactitud, identidad e integridad de la prestación, pues guarda aún vigencia la fórmula del Derecho Romano: aliud pro alio, invito creditori solvi non potest (I. 2, 1, D. 1, así, José Beltrán Heredia y Castaño, El Cumplimiento de las Obligaciones, págs. 209 y sgts. Madrid 1956)./ En las palabras de eminentes autores Cuando la compraventa recaiga sobre un cuerpo cierto, el vendedor está obligado igualmente a entregar la cosa tal y como ha sido convenida, querida por las partes; en consecuencia, si la cosa vendida y entregada está afectada por un vicio oculto, ignorado por el comprador, o si lleva consigo una posibilidad de evicción, el vendedor no ha cumplido con su obligación de entrega (H. L. y J. Mazeaud, Lecciones de Derecho Civil, parte 3, vol., n. 937)./ Pero una vez que un tercero se adelante a reclamar derechos sobre la cosa por causa anterior a la venta, surge para el vendedor la obligación de defensa y saneamiento./ La distinción entre ambas obligaciones es pues más de oportunidad que de diferencia de contenido y es lo que explica en modernas tendencias, se unifiquen ambas en la de entregar./ Asi entonces, desde que las partes convinieron en que el departamento once de calle Infante 145 de la ciudad de Penco se vendia libre de gravámenes y probibición, la vendedora no cumplió con exactitud su deber de entregar lo que reza el contrato, desde que ese inmueble estaba afecto a una hipoteca y una probibición a favor del Banco del Estado, según se ha dicho más arriba".

$\mathrm{Al}$ abrigo de esta sentencia podemos volver a preguntarnos cómo se debe cumplir con la obligación de entrega y quées lo se debe entregar. Y la respuesta a la primera pregunta es que ya no se trata, simplemente del traspaso material y jurídico de la cosa. Sino del traspaso libre de derechos de terceros. Por lo tanto, también hemos respondido a la segunda pregunta, se cumple cuando la cosa esta libre de derechos de terceros. 
Consideraciones similares pueden desprenderse de otras dos sentencias. La primera de ella es una de la Corte de Apelaciones de Antofagasta confirmada por la Corte de Suprema, de 22 de septiembre de $2009^{13}$. Se trata de la venta de un tractor camión, en el contrato se declaró que al vehículo no le afectaba prenda o prohibición alguna y que esa declaración era causal determinante de la celebración del contrato. Sin embargo, existía una prenda y una prohibición de enajenar. La compradora ejerció la acción resolutoria por incumplimiento de la obligación de entrega ${ }^{14}$. La Corte de Apelaciones de Antofagasta consideró incumplida dicha obligación por la presencia de la prohibición de enajenar.

La segunda sentencia es de la Corte de Apelaciones de Santiago, de fecha 10 de julio de $2007^{15}$. El comprador demandante alega el incumplimiento parcial de la obligación de entrega de un inmueble y la correspondiente indemnización de perjuicios toda vez que en el contrato de compraventa se establecía que el inmueble se vendía libre de todo gravamen, prohibición, embargo y juicio pendiente. Sin embargo, existía un contrato de arrendamiento sobre el inmueble y una prenda agraria a favor de una compañía frutera. Conociendo de un recurso de casación en la forma interpuesto por el demandado, la Corte consideró que había existido incumplimiento de la obligación de entrega.

\section{ENTREGA COMO TRADICIÓN Y ENTREGA COMO CONFORMIDAD AL CONTRATO: ¿SON REALMENTE INCONSISTENTES LAS SENTENCIAS?}

Refiriéndose al artículo $1.603 \mathrm{CCFr} .{ }^{16}$ (equivalente al $1.824 \mathrm{CCCh}$. ), Huet señala que "A decir verdad, el estado del Derecho es infinitamente más complejo"17. Mutatis mutandis algo semejante se puede afirmar respecto del artículo 1.824 CCCh.: "Las obligaciones del vendedor se reducen en general a dos: la entrega o tradición, y el saneamiento de la cosa vendida".

A la luz de las sentencias mencionadas en los dos números anteriores parece posible deslindar dos formas diversas de entender la obligación de

${ }^{13}$ Corte Suprema, sentencia de 22 de septiembre 2009, cita Westlaw Chile: CL/ JUR/1235/2009.

${ }^{14}$ En el contrato la vendedora declaró haber recibido el bien a su entera conformidad y renunció a las acciones de saneamiento.

${ }^{15}$ Corte de Apelaciones de Santiago, sentencia de 10 de julio de 2007, cita Westlaw Chile: CL/JUR/1338/2007.

16 "Il a deux obligations principales, celle de délivrer et celle de garantir la chose qu'il vend."

${ }^{17}$ Huet, J., Traité de Droit civil. Les principaux contrats spéciaux (Paris, LGDJ, 1996), p. 176. 
entrega. Sin aspiraciones de precisión técnica -nada más para efectos de claridad expositiva- voy a denominar a la primera de esas formas "entrega como tradición" y a la segunda "entrega como conformidad al contrato".

La primera de ellas corresponde a la forma en que entendió la obligación de entrega la Corte de Apelaciones de Valdivia en la sentencia de 16 de noviembre de $2009^{18}$ es decir como una entrega que se agota en un traspaso material y jurídico de la cosa. La segunda forma es la que utilizó la Corte de Apelaciones de Concepción de 1 de diciembre de 1993, es decir como una entrega libre de derechos de terceros ${ }^{19}$.

Ahora bien, que estas sentencias -y otras- asuman la obligación de entrega de estas dos maneras no es, en principio, jurídicamente preocupante. Lo que sí sería preocupante, en términos de certeza jurídica e igualdad ante la ley, es que resultasen inconsistentes. Es decir que para casos jurídicamente asimilables fallen de forma diversa.

Pero eso no sucede en las sentencias que he considerado aquí, o al menos eso es lo que voy a sostener en los números siguientes. Una mirada a las sentencias presentadas muestra que, no obstante se sirvan de formas de distintas de entender la obligación de entrega, son compatibles. El punto no es exactamente que se sirvan de formas distintas de entender la obligación de entrega, sino por qué lo hacen. Al comprender la respuesta a esta última pregunta se advierte la compatibilidad entre las sentencias.

\section{LA ACTIVIDAD DEL TERCERO, UN CRITERIO POCO PERSUASIVO}

Quizás la primera tentación consista en afirmar que las sentencias no resultan incompatibles toda vez que, si bien es cierto que utilizan formas distintas de entender la obligación de entrega, esto se explica porque se refieren a momentos distintos. Esta explicación puede ilustrarse acudiendo a la sentencia de la Corte de Apelaciones de Concepción de 1 de diciembre de 1993. Recordemos parte de su contenido: "En las palabras de eminentes autores, cuando la compraventa recaiga sobre un cuerpo cierto, el vendedor está obligado igualmente a entregar la cosa tal y como ha sido convenida, querida por las partes; en consecuencia, si la cosa vendida y entregada está afectada por un vicio oculto, ignorado por el comprador, o si lleva consigo una posibilidad de evicción, el vendedor no ha cumplido con su obligación de entrega (H. L. y J. Mazeaud, Lecciones de Derecho Civil, parte 3, vol., n. 937)./ Pero una vez que un tercero se adelante a reclamar derechos sobre la cosa por causa anterior a la venta, surge para el vendedor la obligación de defensa y saneamiento".

\footnotetext{
${ }^{18}$ Véase la n. 6.

${ }^{19}$ Véase la n. 11.
} 
Entonces, podríamos afirmar que mientras el tercero no ha notificado judicialmente al comprador debemos entender la entrega como conformidad al contrato. Pero, una vez que ha tenido lugar dicha notificación, entendemos la entrega como tradición. Para decirlo en forma más clara: mientras el tercero no ha notificado consideraremos que la presencia de derechos de terceros ha de entenderse como un incumplimiento de la obligación de entrega que autoriza recurrir al régimen general de los remedios del incumplimiento contractual. Sin embargo, después de la notificación esto no es posible y sólo puede buscar tutela en el régimen de la evicción.

Puede ser, pero en mi opinión se trata de un criterio poco persuasivo para defender la compatibilidad de las sentencias. Por cuatro razones.

La primera de ellas es que no resulta convincente que por el hecho de la notificación se alteren las consecuencias del incumplimiento de la obligación de entrega. Si se asume que existió un incumplimiento de la obligación de entrega que autoriza recurrir a las acciones generales del incumplimiento contractual, el hecho de que el tercero notifique no debería privar al comprador de esas acciones.

En segundo lugar, para que este criterio tuviera esa fuerza explicativa sería necesario que de la lectura de la sentencia de la Corte de Apelaciones de 1 de diciembre de $1993^{20}$ se desprendiera que una vez notificada la acción intentada por el tercero ya no es posible servirse de las acciones propias del régimen general del incumplimiento. Pero, como acabamos de ver, no dice eso; se limita a señalar que "surge para el vendedor la obligación de defensa y saneamiento".

En tercer lugar, aún cuando las dos razones anteriores no resulten persuasivas, la tercera tiene entidad suficiente como para desechar este criterio. Se trata de la sentencia de la Corte de Apelaciones de Valdivia ${ }^{21}$. En particular del considerando duodécimo en la siguiente parte: "Que, entonces, sijuridicamente no constituye incumplimiento contractual (de la obligación de entregar en la compraventa) el hecho de que todo el objeto del contrato (la totalidad del predio, en la especie) resulte ser de dominio ajeno, entonces, a fortiori, menos puede serlo la circunstancia de que una sección menor del mismo sea objeto de disputa dominical, como ocurre en la especie".

Es decir, en opinión de la Corte nunca existió incumplimiento de la obligación de entrega porque el vendedor no se obligó a una entrega libre de derechos de terceros.

Existe todavía una cuarta razón y es que si se mira con cuidado la sentencia

${ }^{20}$ Véase la n. 11.

${ }^{21}$ Véase la n. 6. 
de la Corte de Apelaciones de Concepción de 1 de diciembre de $1993^{22}$ no dice que la obligación de entrega únicamente se entiende cumplida cuando la cosa se traspasa libre de derechos de terceros, sino que en ese caso particular no se entendía cumplida.

Precisar por qué en ese caso no se entendía cumplida nos lleva al siguiente criterio.

\section{LA AUTONOMÍA PRIVADA}

El considerando tercero de la sentencia de la Corte de Apelaciones de Concepción de 1 de diciembre de $1993^{23}$ se señala: "Que en dicha compraventa, cláusula cuarta, se dijo por las partes que la venta se hacía en el estado que se encuentra actualmente el departamento, con todos sus usos, derechos, costumbres y servidumbres, libre de todo gravamen, probibición y embargo, con todo lo edificado y planteado". Y el considerando séptimo añade: "Por su parte, la obligación de entregar implica entre nosotros, tanto la de hacer la tradición, como la de pasar materialmente la cosa a poder del comprador.l Pero lo que el vendedor ha de entregar es la misma cosa que se individualiza en el contrato y esa obligación sólo se cumple si lo entregado es la cosa tal y como ha sido convenida, de forma que, faltándole alguna parte o afectándole algún derecho en favor de un tercero que pueda producir su evicción, el vendedor no ha cumplido cabalmente su obligación".

Al considerar ambos extractos en conjunto resulta bastante evidente que la Corte no está reflexionando sobre la obligación de entrega in abstracto, sino in concreto a la luz de las estipulaciones contractuales de las partes. Esto se advierte con toda comodidad cuando la Corte fija la pregunta que debe responder. Como se recordará: "[...] la cuestión a decidir, en primer término, es si la obligación de entregar la cosa vendida, que el artículo 1824 del Código Civil pone de cargo del vendedor, comprende o no la de transferirsela libre de gravámenes o derechos en favor de terceros, cuando el vendedor ha declarado vender una especie libre de ellos y si,por lo mismo, la demandada ha cumplido o no esa obligación" ${ }^{24}$.

De todo esto se puede desprender una conclusión general y es que lo que sucede no es que la obligación de entrega, digamos, naturalmente exigiera al traspaso de la cosa sin derechos de terceros, sino que el acuerdo de las partes -digamos esta vez, accidentalmente- le concedió esa virtualidad. Por lo tanto, si el vendedor entrega la cosa con derechos de terceros cumple imperfecta-

\footnotetext{
${ }^{22}$ Véase la n. 11.

${ }^{23}$ Ibíd..

${ }^{24}$ Espaciado añadido.
} 
mente, porque, como ha sostenido la Corte Suprema en su sentencia de 8 de septiembre de 200925: "[...] la falta de cualquier aspecto que comprenda la obligación de hacer entrega de la especie objeto del contrato de compraventa, por parte del vendedor al comprador, importa incumplimiento de la misma. Por lo mismo, la satisfacción de una o más de tales particularidades determina el cumplimiento parcial de la obligación por parte del vendedor".

Ahora bien, antes de considerar si este criterio resulta persuasivo para justificar que el uso por parte de los dos tribunales de las dos formas de entender la entrega en las diversas sentencias no resulta inconsistente me interesa detenerme sobre una cuestión previa que consiste en determinar si las partes, a través de sus acuerdos, pueden modificar la obligación de entrega.

Mi opinión es, desde luego, que sí. Pero éste, afortunadamente, no es mi mejor argumento. Mi argumento es que la doctrina más autorizada a nivel nacional y comparado lo estima de esta manera. Comenzado por la primera, la cita obligada es Alessandri Rodríguez Según este autor: "Las obligaciones propias del vendedor y que nacen del contrato de venta por el solo efecto de celebrarse sin necesidad de que las partes, es decir, las obligaciones que la ley impone son dos: la entrega de la cosa y el saneamiento de la misma. Sin perjuicio de ellas, los contratantes pueden estipular otras o atenuar o modificar esas dos. En tal caso deben pactarse expresamente, pues, a falta de tal convenido, el vendedor no tiene sino las señaladas por la ley y en la extensión que ésta establece" 26 .

Entonces, según este autor, la compraventa establece naturalmente un par de obligaciones para el vendedor, sin embargo, las partes pueden modificarlas -en este caso, la de entrega-y si lo hacen, no es la configuración natural de las obligaciones lo que los obliga, sino el pacto.

Si se continúa con la doctrina extranjera, resultan especialmente clarificadoras las palabras de Luis Díez-Picazo: "Ninguna duda suscita la posibilidad de que la obligación de transmitir la propiedad se establezca mediante un convenio expreso, que pueda, además, ir acompañado de un pacto resolutorio expreso para el supuesto de que tal obligación no se llegue a ejecutar" 27 .

Como puede advertirse, el profesor español endereza sus conclusiones respecto de la venta de cosa ajena, pero como nos enseña la sentencia de la Corte de Apelaciones de Valdivia ${ }^{28}$ lo que se dice de la venta de cosa ajena, $a$ fortiori puede predicarse de los casos que interesan a este trabajo.

Advertido que las partes pueden modificar la obligación de entrega resulta

\footnotetext{
${ }^{25}$ Véase la n. 1.

${ }^{26}$ AlessAndri Rodríguez, cit. (n. 8), p. 573.

${ }^{27}$ DíEz-Picazo, L., Fundamentos del Derecho civil patrimonial, IV: Las particulares relaciones obligatorias (Cizur Menor Thomson Reuters, 2010), pp. 60-62.

${ }^{28}$ Véase la n. 6.
} 
necesario determina si la autonomía de la voluntad es un criterio que nos permita explicar el uso de las distintas formas de entender la obligación de entrega que es posible deslindar de las sentencias que he presentado.

Comienzo por el grupo de sentencias que consideran que se incumple con la obligación de entrega cuando se traspasa una cosa con derechos de terceros, y entiendo que, a estas alturas, no resulta necesario volver a referirse a la sentencia de la Corte de Apelaciones de Concepción de 1 de diciembre de $1993^{29}$, por lo tanto sigo con la de la Corte de Apelaciones de Antofagasta de 22 de septiembre de 2009 sobre el tracto camión ${ }^{30}$. Según se desprende del considerando segundo de la sentencia: "De acuerdo a la cláusula tercera del pacto [...] la demandada declaró que al vehiculo no le afectaba prenda o probibición alguna y que esa declaración era causal determinante para la celebración del contrato. Por lo tanto, concluyen, la tradición es entrega sin prenda ni probibiciones".

Entonces, una vez más, parece ser determinante en la comprensión de la obligación de entrega por parte del tribunal la existencia del pacto entre las partes que la modela, añadiendo que la cosa debe estar libre de prendas y derechos de terceros, por eso la incumple quien entrega un camión con una prenda y una prohibición de enajenar. Algo semejante sucede con la sentencia de la Corte de Apelaciones de Santiago de 10 de julio de $2007^{31}$ en donde parece haber sido central el hecho de que la cláusula cuarta del contrato disponía que el inmueble se vendía "libre de todo gravamen, probibición, embargo y juicio pendiente".

Podemos volver ahora sobre el par de sentencias que se sirven de la noción de entrega como tradición y considerar si lo que explica esto es la ausencia de un pacto que modele la obligación de entrega. Así parece suceder en la sentencia de la Corte de Apelaciones de Concepción de 9 de enero de $2002^{32}$ en la cual no se menciona la existencia de dicho pacto, sino, más bien la existencia de uno según el cual: "el comprador declara haber recibido en dicho acto y después de haberlos revisado detenidamente y a su entera satisfacción, por lo que expresa no tener cargo alguno ni objeción que formular".

Más compleja, sin embargo, es la sentencia de la Corte de Apelaciones de Valdivia de 16 de noviembre de $2009^{33}$. La razón de la complejidad radica en que en ella existía una cláusula que modelaba la obligación de entrega y exigía que fuera "libre de todo gravamen, probibición, embargo y juicio pen-

\footnotetext{
${ }^{29}$ Véase la n. 11.

${ }^{30}$ Véase la n. 13

${ }^{31}$ Véase la n. 15.

${ }^{32}$ Véase la n. 10.

${ }^{33}$ Véase la n. 6.
} 
diente”. ¿Por qué, entonces la Corte no se tomó en serio el pacto de las partes y declaró, como lo solicitaba el comprador, resuelto el contrato?

Una posible respuesta es que la Corte sí respetó la autonomía de privada de las partes, lo que sucede es que interpretó ésta con mayor precisión que el demandante. Para comprender esto, habrá que advertir que junto a la cláusula que modelaba la obligación de entrega había otra que denominaré "de conformidad", según la cual el comprador declaró expresamente "haber recibido materialmente a su entera conformidad la propiedad raiz materia de este contrato". De hecho, en el considerando décimo cuarto de la sentencia el Tribunal indica que considerar que existió un incumplimiento contractual contraviene el artículo $1545 \mathrm{CCCh}$. porque en el contrato existe esta cláusula de conformidad.

La organización de la convivencia de ambas cláusulas -la que modelaba la obligación de entrega y la de conformidad precisa, en mi opinión establecer el alcance de la cláusula de conformidad.

Creo que se puede reflexionar sobre esto considerando que la cláusula de conformidad, tal y como la entendió el Tribunal, es una cláusula de renuncia: porque la entrega fue conforme no puedo luego alegar su incumplimiento. Al considerar la cláusula de conformidad como una de renuncia es necesario pensar bajo qué condiciones resultan eficaces este tipo de cláusulas y el material normativo que se encuentra más cercano son las cláusulas de renuncia propias de la evicción. Desde luego no es necesario tratarla monográficamente, sino nada más, considerar las circunstancias que limitan su eficacia. Tratándose del artículo 1.852 CCCh. -es decir en el caso de la evicción- la cláusula de renuncia logra plena eficacia en dos situaciones: " $s i$ el que compró lo hizo a sabiendas de ser ajena la cosa, o si expresamente tomó sobre si el peligro de la evicción, especificándolo". En palabras de Alessandri Rodríguez la justificación de esta regla se encuentra en la asunción del riesgo por parte del comprador ${ }^{34}$. Ahora bien, como puede verse, la eficacia de la cláusula supone conocimiento de los derechos del tercero o bien asunción ¿Resulta posible cuadrar la cláusula de conformidad con alguno de esos dos supuestos? Aparentemente sí. En opinión del demandado, el demandante siempre estuvo en conocimiento de la imperfección de los deslindes sobre los cuales se reclamaron derechos de terceros, pues el mismo acompañó al juicio el informe de títulos que le proporcionó el Banco en el cual se daba noticia de estos. Si esto es correcto entonces quiere decir que la adecuada interpretación de la cláusula que modelaba la entrega determina que su alcance no puede extenderse a aquellas imperfecciones que el comprador conocía o no podía ignorar.

${ }^{34}$ Alessandri Rodríguez, A., De la compraventa, cit. (n. 8), II,1, p. 170. 


\section{CONCLUSIÓN}

En este trabajo he sostenido que en los conocidos problemas de entrega de cosas en la cual hay derechos de terceros los tribunales han entendido la obligación de entrega de dos formas diversas. He denominado a una de ellas "entrega como tradición" y a la otra "entrega como conformidad con el contrato.

Me ha interesado defender la idea de que la aplicación de estas dos formas no resulta inconsistente. El criterio que, en mi opinión, permite determinar cuando han entendido de una manera u otra la obligación de entrega es la autonomía privada.

En otras palabras, si no existe un acuerdo entre las partes que modele la obligación de entrega, los tribunales han entendido que el cumplimiento de ésta no exige que la cosa se entregue libre de derechos de terceros. Si se entrega con derechos de terceros, el comprador debe buscar su protección en la disciplina de la evicción. Si, en cambio, el vendedor se obligó a entregar una cosa libre de derechos de terceros, el traspaso de la cosa con derechos de terceros incompatibles con el pacto determina el incumplimiento de la obligación de entrega y el comprador podrá buscar tutela en el régimen general de las acciones propias del incumplimiento contractual.

Me parece que esta idea permite organizar adecuadamente las sentencias a las que me he referido en este trabajo. Sin embargo, lo que no permite asegurar una muestra de sentencias tan modesta como la que he empleado aquí es que esta idea refleje adecuadamente la práctica general de los tribunales superiores chilenos. Para afirmar algo como esto se requiere un estudio con un compromiso metodológico mucho más ambicioso que el de éste.

Finalmente, he sostenido que la voluntad puede modelar la obligación, pero no es lo único que puede modelarla exigiendo el traspaso de la cosa libre de derechos de terceros. El segundo dispositivo corresponde al principio general de la buena $\mathrm{fe}^{35}$. Si no me he referido a él aquí es, simplemente, porque no he sabido encontrar sentencias nacionales que lo empleen de esta manera.

\section{BibliografíA}

Alessandri Rodríguez, A., De la compraventa y de la promesa de venta (reimpresión Santiago, Editorial Jurídica de Chile, 2003).

De la Maza Gazmuri, Iñigo, El régimen de los incumplimientos defectuosos en la compraventa (inédito).

${ }^{35}$ Me he referido a esto en DE la MAZA Gazmuri, cit. ( n. 5). 
Díez-Picazo, L., Fundamentos del Derecho civil patrimonial, IV: Las particulares relaciones obligatorias (Cizur Menor Thomson Reuters, 2010).

Goldie-Genicon, Ch., Contribution à l'étude des rapports entre le droit commun et le droit special des contrats (París, LGDJ, 2009).

Huet, J., Traité de Droit civil. Les principaux contrats spéciaux (Paris, LGDJ, 1996).

SQUella NARDuCCI, A., Introducción al derecho (Santiago, Editorial Jurídica de Chile, 2011).

UGARTE GODOY, Joaquín, La obligación esencial del vendedor de transferir el dominio, en Mac Hale, Thomas - del Valle, Jaime, Estudios en honor a don Pedro Lira Urquieta (Santiago, Editorial Jurídica de Chile, 1970).

Verda y Beamonte, Jr., Saneamiento por vicios ocultos, (2a edición, Cizúr Menor, Aranzadi Thonson Reuters). 